\title{
Article \\ Effects of Sugars and Degradation Products Derived from Lignocellulosic Biomass on Maleic Acid Production
}

\author{
So-Yeon Jeong ${ }^{1}$ and Jae-Won Lee ${ }^{1,2, *}$ \\ 1 Department of Wood Science and Engineering, College of Agriculture and Life Sciences, \\ Chonnam National University, Gwangju 61186, Korea; thdus9603@naver.com \\ 2 Interdisciplinary Program in IT-Bio Convergence System, Chonnam National University, \\ Gwangju 61186, Korea \\ * Correspondence: ljw43376@chonnam.ac.kr; Tel.: +82-625302098
}

check for updates

Citation: Jeong, S.-Y.; Lee, J.-W.

Effects of Sugars and Degradation

Products Derived from

Lignocellulosic Biomass on Maleic Acid Production. Energies 2021, 14, 918. https://doi.org/10.3390/ en14040918

Academic Editors: Bonwook Koo and Attilio Converti

Received: 18 January 2021

Accepted: 6 February 2021

Published: 9 February 2021

Publisher's Note: MDPI stays neutral with regard to jurisdictional claims in published maps and institutional affiliations.

Copyright: (c) 2021 by the authors. Licensee MDPI, Basel, Switzerland. This article is an open access article distributed under the terms and conditions of the Creative Commons Attribution (CC BY) license (https:/ / creativecommons.org/licenses/by/ $4.0 /)$.

\begin{abstract}
In this study, maleic acid was produced from xylose contained in a hydrolysate generated by oxalic acid pretreatment of yellow poplar (Liriodendron tulipifera), and the factors that influenced maleic acid production were evaluated. Furfural was obtained from the hydrolysate using $\mathrm{H}_{2} \mathrm{SO}_{4}$ as a catalyst, depending on combined severity factors (CSFs). Furfural production increased as the $\mathrm{H}_{2} \mathrm{SO}_{4}$ concentration increased. Furfural yield (46.70\%), xylose conversion (70.95\%), and xylo-oligomer conversion (75.47\%) from the hydrolysate were high at CSF 1.92 with $1.64 \% \mathrm{H}_{2} \mathrm{SO}_{4}$. However, the furfural concentration was slightly increased at $1.64 \% \mathrm{H}_{2} \mathrm{SO}_{4}$ to $7.10 \mathrm{~g} / \mathrm{L}$ at CSF 1.89 , compared with that at CSF 1.92. Maleic acid was produced from the hydrolysate (CSF 1.92 and $\left.1.64 \% \mathrm{H}_{2} \mathrm{SO}_{4}\right)$ at a yield of $91.44 \%$. Maleic acid production was slightly better when formic acid and acetic acid were included in the hydrolysate than when furfural was included alone (79.94\% vs. $78.82 \%)$. Based on the results, the xylose obtained from yellow poplar can be proposed as a new substitute for fossil fuel-derived raw materials.
\end{abstract}

Keywords: xylose; furfural; maleic acid; hydrolysate; lignocellulosic biomass

\section{Introduction}

A biorefinery that could produce biofuels and bio-based chemicals through the biological and chemical conversion of lignocellulosic biomass is a promising idea that could help offset the depletion of fossil fuels and the effects of climate change. Lignocellulosic biomass mainly consists of cellulose, hemicellulose, and lignin, which are not easily decomposed. Therefore, the efficient utilization of lignocellulosic biomass requires physical, chemical, and/or biological pretreatment [1]. Among such methods, high efficiency has been achieved using acid catalysts [2-4]. Sugars and various degradation products, such as organic acid, furfural, 5-hydroxymethylfurfural (HMF), and phenolic compounds, are simultaneously produced during pretreatment [5]. The sugars can be used to produce bioenergy and bio-based products, while the degradation products inhibit subsequent processing (enzymatic hydrolysis and fermentation).

Among the degradation products, furfural is one of the top 12 value-added products defined by the U.S. Department of Energy, and it is a precursor that can be applied to the fuel, plastic, cosmetic, and pharmaceutical industries [6-8]. Lignocellulosic biomass, such as that comprising corn and sugar cane, is the raw material for furfural production, and 250,000 tons of furfural are produced annually through hemicellulose hydrolysis to xylose and xylose dehydration to furfural using acid catalysts $[9,10]$. Furfural is used as a precursor for maleic acid production in which HMF or furfural is the starting material derived from glucose or xylose [11]. Maleic acid is an intermediate of chemical synthesis that is widely applied in medicines, pesticides, and foods [12]. Maleic acid cannot be produced biochemically, and it is industrially derived from the oxidation of butane, butadiene, or 
benzene at high temperatures, with catalysts such as vanadium oxides or vanadiumphosphorous [12,13]. To produce about 2 million tons of maleic acid per year, bio-based and eco-friendly feedstock must be developed, and a cost-effective process is required [8]. Maleic acid is presently chemically synthesized from furfural in response to excessive fossil fuel consumption. Maleic acid is produced based on chemical oxidation using a catalyst and electrochemical oxidation. In particular, maleic acid is usually produced by oxidation using $\mathrm{H}_{2} \mathrm{O}_{2}$ [14]. This process can increase the maleic acid yield to $70 \%$ by the selective oxidation of furfural when $\mathrm{H}_{2} \mathrm{O}_{2}$ is combined with a catalyst and titanium silicalite-1, and to $60 \%$ when combined with betaine hydrochloride [14,15].

However, the process is problematic owing to catalyst reuse and complex reaction conditions at high temperatures and pressure [8]. Lignocellulosic biomass has received attention for producing valuable organic acids, such as formic, acetic, maleic, and succinic acids [16]. Most studies have produced maleic acid via the hydrolysis of hemicellulose/cellulose into xylose/glucose. A few studies have applied hydrolysates generated by dilute acid pretreatment of lignocellulosic biomass [17-19]. Maleic acid production using hydrolysate derived from lignocellulosic biomass, which contains an abundance of monosaccharides, can be regarded as a new eco-friendly process.

The reaction pathway for maleic acid production from lignocellulosic biomass can be predicted (Scheme 1). Xylose is initially produced from hemicellulose by pretreatment, then dehydrated to furfural using an acid catalyst. 2- $(5 \mathrm{H})$ furanone is produced by the Baeyer-Villiger oxidation of furfural, and maleic acid is produced by the oxidation of 2-(5H) furanone [15]. Hydrolysates contain monosaccharides (such as xylose and glucose) and various organic acids, and formic and acetic acids promote maleic acid production. Thus, hydrolysates might contain an abundance of precursors for maleic acid production. Here, yellow poplar (Liriodendron tulipifera) was pretreated using oxalic acid, which selectively degrades hemicellulose, to obtain xylose-rich hydrolysates. Then, the sequential production of furfural and maleic acid was evaluated by dehydrating xylose and oxidizing furfural. Additionally, the effects of various chemicals in the hydrolysate on maleic acid production were investigated.

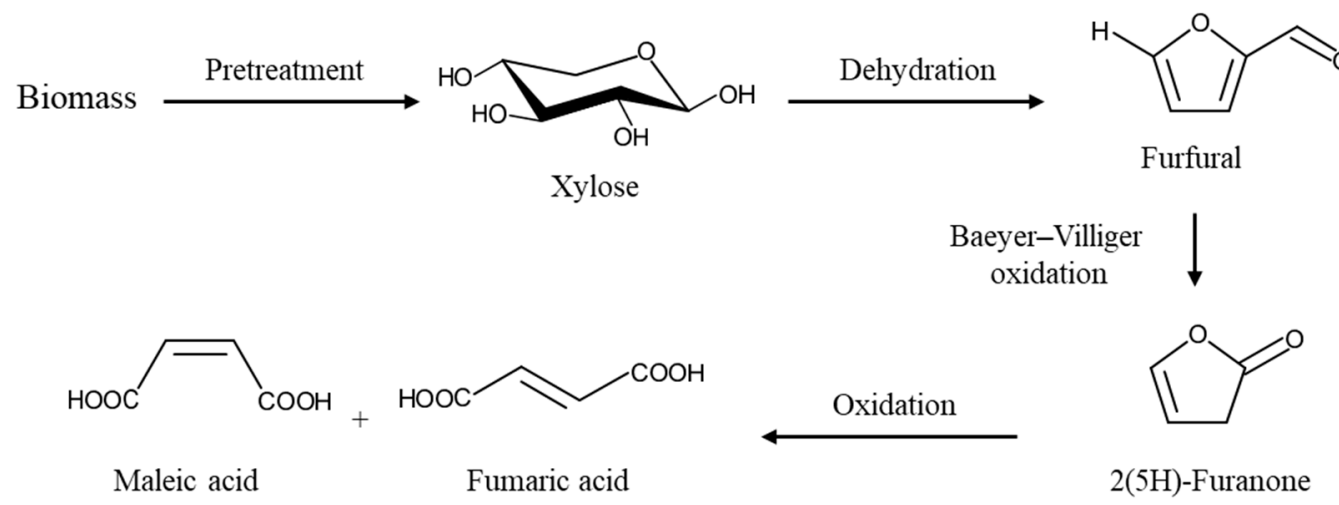

Scheme 1. Conversion of lignocellulosic biomass to maleic acid.

\section{Materials and Methods}

\subsection{Hydrolysate Production from Yellow Poplar Pretreatment with Oxalic Acid}

Furfural and maleic acid were produced from the first hydrolysate, as described [20]. Yellow poplar (Liriodendron tulipifera) powder (20-80 mesh) was reacted with various concentrations of oxalic acid at $160^{\circ} \mathrm{C}$ (Table 1). Table 2 shows the chemical composition of the first hydrolysate [20]. The schematic diagram of the entire experiment in this study is shown in Figure 1. The experiments were performed in triplicate. 
Table 1. Pretreatment of yellow poplar using oxalic acid [20].

\begin{tabular}{cccc}
\hline Sample No. & Time $(\mathbf{m i n})$ & Acid Concentration $(\mathbf{m M})$ & CSF $^{*}$ \\
\hline 1 & \multirow{2}{*}{30} & 82 & 1.89 \\
2 & & 139 & 2.08 \\
\hline 3 & \multirow{2}{*}{50} & 41 & 1.92 \\
4 & & 122 & 2.29 \\
\hline
\end{tabular}

${ }^{*}$ Combined severity factors $(\mathrm{CSFs})=\log \left\{t \times \exp \left[\left(\mathrm{T}_{\mathrm{H}}-\mathrm{T}_{\mathrm{R}}\right) / 14.75\right]\right\}-\mathrm{pH}\left(t\right.$ : pretreatment reaction time $(\mathrm{min}), \mathrm{T}_{\mathrm{H}}$ reaction temperature $\left({ }^{\circ} \mathrm{C}\right), \mathrm{T}_{\mathrm{R}}$ : reference temperature, most often $100{ }^{\circ} \mathrm{C}$, and $\mathrm{pH}$ : acidity of aqueous solution).

Table 2. Sugars, xylo-oligomer, and inhibitors in first hydrolysate, depending on oxalic acid pretreatment conditions [20].

\begin{tabular}{ccccccccc}
\hline \multirow{2}{*}{ CSF } & Glu & Xyl & XO & FA & AA & HMF & Fur & \multirow{2}{*}{ pH } \\
\cline { 2 - 6 } & & & & g/L & & & & \\
\hline \multirow{2}{*}{1.89} & 3.02 & 15.17 & 2.50 & 2.12 & 8.02 & 0.21 & 1.95 & 2.10 \\
& $(0.22)$ & $(0.62)$ & $(0.25)$ & $(0.11)$ & $(0.14)$ & $(0.01)$ & $(0.05)$ & $(0.02)$ \\
\hline \multirow{2}{*}{1.92} & 2.46 & 14.95 & 2.65 & 1.33 & 8.33 & 0.22 & 1.73 & 2.19 \\
& $(0.16)$ & $(0.89)$ & $(0.18)$ & $(0.30)$ & $(0.33)$ & $(0.03)$ & $(0.12)$ & $(0.05)$ \\
\hline \multirow{2}{*}{2.08} & 3.69 & 14.37 & 2.06 & 2.67 & 7.95 & 0.27 & 2.45 & 1.84 \\
& $(0.19)$ & $(0.37)$ & $(0.19)$ & $(0.36)$ & $(0.12)$ & $(0.08)$ & $(0.45)$ & $(0.03)$ \\
\hline \multirow{2}{*}{2.29} & 4.26 & 12.80 & 1.99 & 2.59 & 8.19 & 0.38 & 3.37 & 2.00 \\
& $(0.02)$ & $(0.63)$ & $(0.34)$ & $(0.37)$ & $(0.14)$ & $(0.05)$ & $(0.32)$ & $(0.07)$ \\
\hline
\end{tabular}

The first hydrolysate was obtained from oxalic acid pretreatment of yellow poplar. Glu: Glucose, Xyl: Xylose, $\mathrm{XO}$ Xylo-oligomer, FA: Formic acid, AA: Acetic acid, HMF: 5-Hydroxymethylfurfural, Fur: Furfural. The numbers in parentheses indicate the standard deviation.

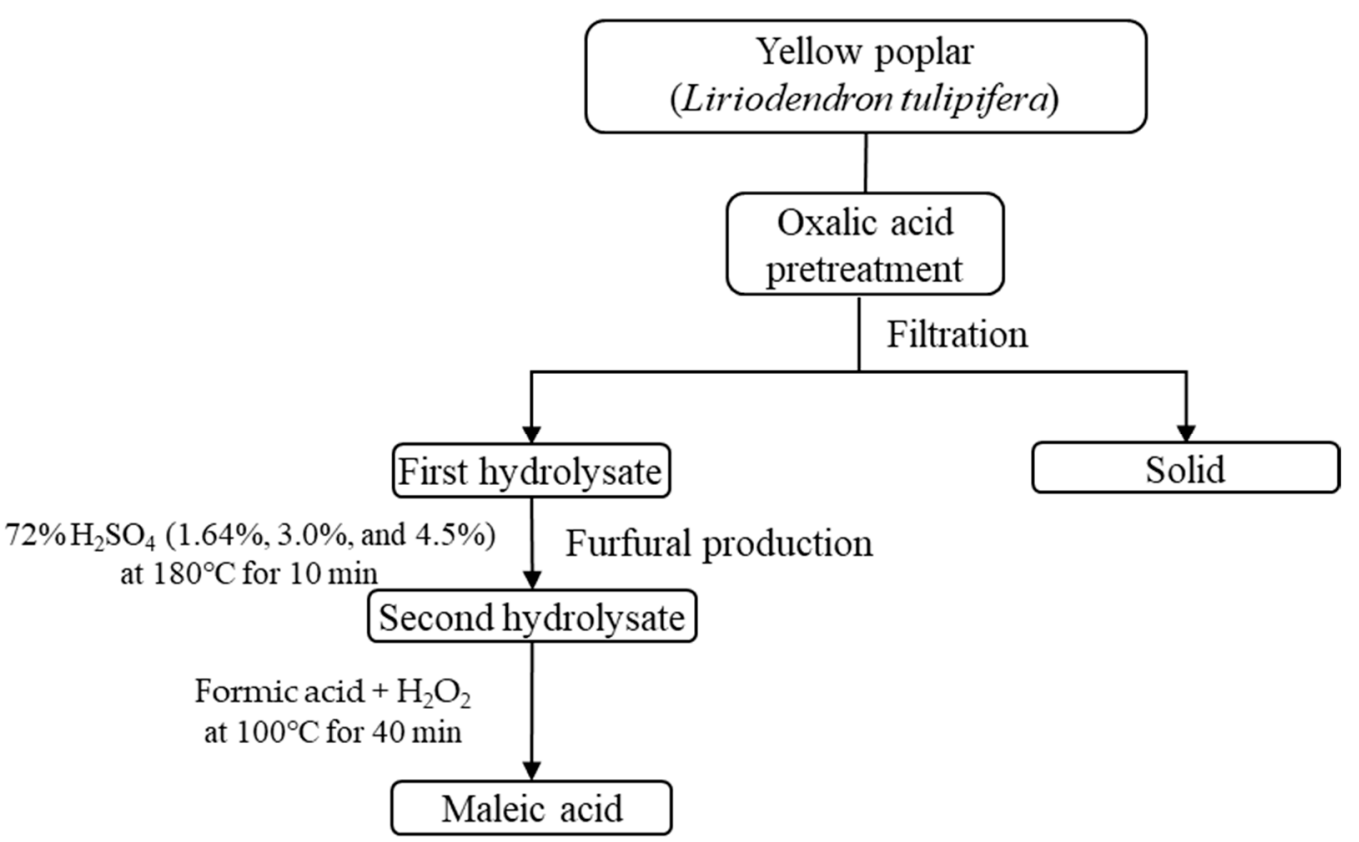

Figure 1. Maleic acid production from yellow poplar.

\subsection{Furfural Production Using the First Hydrolysate}

The first hydrolysate $(3 \mathrm{~mL})$ was added to $72 \% \mathrm{H}_{2} \mathrm{SO}_{4}(0.07,0.13$, and $0.2 \mathrm{~mL})$ in test tubes with screw caps. The final $\mathrm{H}_{2} \mathrm{SO}_{4}$ concentrations in the mixtures were $1.64 \%$, $3.0 \%$, and $4.5 \%$, respectively. Reactions proceeded in the test tubes placed in an oil bath under constant magnetic stirring. The reaction temperature was increased to $180{ }^{\circ} \mathrm{C}$ and held for $10 \mathrm{~min}$; then, the mixture was cooled and separated into solid (humin) and liquid (second hydrolysate) fractions. The chemical composition of the second hydrolysate 
was analyzed by high-performance liquid chromatography (HPLC). Furfural yield, xylose conversion, xylo-oligomer conversion, and furfural selectivity were calculated using Equations (1)-(4) [6,21]. The experiments were performed in triplicate.

Yield of furfural $(\%)=$ furfural produced $(\mathrm{mol}) /$ starting xylose + starting xylo-oligomer $(\mathrm{mol}) \times 100$

Conversion of xylose $(\%)=$ xylose reacted $(\mathrm{mol}) /$ starting xylose $(\mathrm{mol}) \times 100$

Conversion of xylo-oligomer $(\%)=$ furfural produced $(\mathrm{mol}) /$ starting xylo-oligomer $(\mathrm{mol}) \times 100$

Selectivity of furfural $(\%)=$ furfural produced $(\mathrm{mol}) /$ xylose reacted + xylo-oligomer reacted $(\mathrm{mol}) \times 100$

\subsection{Maleic Acid Production Using the Second Hydrolysate}

Maleic acid was produced using the second hydrolysate with the modified method of $\mathrm{Li}$ et al. [22]. The second hydrolysate $(4 \mathrm{~mL})$ was mixed with formic acid $(1,2.5$, and $4 \mathrm{~mL})$ and $\mathrm{H}_{2} \mathrm{O}_{2}(30 \%, w / w, 4,2.5$, and $1 \mathrm{~mL})$. The total volume of the reaction mixture was $9 \mathrm{~mL}$. The reaction was carried out at $100{ }^{\circ} \mathrm{C}$ for $40 \mathrm{~min}$ in the oil bath. The reaction mixture was cooled; then, the chemical composition of the liquid fraction (3rd hydrolysate) was analyzed by HPLC. The experiments were performed in triplicate. The yields of maleic acid and the intermediate product were calculated using Equation (5) [23]:

Yield of maleic acid $(\%)=$ maleic acid produced $(\mathrm{mol}) /$ starting furfural $(\mathrm{mol}) \times 100$

\subsection{Analysis of Factors Affecting Maleic Acid Production}

Synthetic chemical mixtures of furfural, acetic acid, and formic acid were prepared to analyze their effects on maleic acid production. The chemical concentrations were controlled based on those in the second hydrolysate. The reaction conditions were as described in Section 2.3. The experiments were performed in triplicate.

\subsection{Analysis of the Hydrolysate}

Sugars and degradation products in the hydrolysate were analyzed with HPLC using a Waters 2695 system (Waters Corp., Milford, MA, USA) equipped with a $300 \times 7.8 \mathrm{~mm}$ Aminex 87H column (Bio-Rad Laboratories Inc., Hercules, CA, USA) and a refractive index detector (Waters Corp., 2414). The flow rate of the eluent, $5 \mathrm{mM} \mathrm{H}_{2} \mathrm{SO}_{4}$, was $0.6 \mathrm{~mL} / \mathrm{min}$. The intermediates generated from maleic acid production, such as fumaric acid and 2-(5H)furanone, were analyzed by HPLC Waters 2695 , using a C18 column $(4.6 \times 250 \mathrm{~mm})$ and a UV/Vis detector (Waters 2489, Milford, MA, USA). The mobile phase was a 2:8 ratio of methanol and $1 \%$ phosphoric acid, and the flow rate was $0.6 \mathrm{~mL} / \mathrm{min}$ [12]. The xylooligomer was determined using the National Renewable Energy Laboratory procedure [24]. All experiments were performed in triplicate.

\subsection{Statistical Analysis}

The factors affecting maleic acid production were assessed by one-way analysis of variance (ANOVA), using SPSS version 23 (IBM Corp., Armonk, NY, USA). Correlations between variables were determined using Duncan's tests. Results with a $p$-value of $<0.05$ were considered significantly different.

\section{Results and Discussion}

\subsection{Furfural Production from the First Hydrolysate}

Furfural is produced by the sequential hydrolysis and dehydration of pentosans in lignocellulose under aqueous mineral acid conditions [25]. In this study, furfural was produced from the first hydrolysate of oxalic acid-pretreated yellow poplar, using the acid catalyst $\mathrm{H}_{2} \mathrm{SO}_{4}$, which promotes the dehydration of pentose sugars, such as xylose and arabinose; thus, the amount of furfural produced differs depending on the acid concentration [26]. Because furfural is a maleic acid precursor, high concentrations of furfural in hydrolysates are favorable for maleic acid production. Figure 2 shows the 
amount of furfural produced from the first hydrolysate using various $\mathrm{H}_{2} \mathrm{SO}_{4}$ concentrations. Xylose and xylo-oligomer were converted into furfural, and more furfural was converted with all CSF as the $\mathrm{H}_{2} \mathrm{SO}_{4}$ concentration increased. However, the furfural yield and furfural selectivity decreased with increasing $\mathrm{H}_{2} \mathrm{SO}_{4}$ concentrations. This is because some xylose is not converted to furfural because of the production of humin and furan during the dehydration reaction at high acid concentrations $[21,26,27]$. The factors involved in furfural production are reaction temperature, $\mathrm{pH}$, reaction time, and the catalyst [25]. Among these, temperatures $>170{ }^{\circ} \mathrm{C}$ and a low $\mathrm{pH}$ decrease the yield of thermally unstable furfural [28]. Therefore, furfural yield and selectivity were low in $4.5 \% \mathrm{H}_{2} \mathrm{SO}_{4}$ at all CSFs in this study. However, the furfural yield was relatively high in $1.64 \% \mathrm{H}_{2} \mathrm{SO}_{4}$ at all CSFs. The furfural yield was compared by preparing a synthetic medium with the same concentration as xylose obtained from the first hydrolysate (Figure 3). The furfural yield was higher in the first hydrolysate than in the synthetic medium. The first hydrolysate contained xylooligomer, a precursor of furfural, and formic acid and acetic acid, which can act as catalysts in the furfural production; thus, the furfural yield from hydrolysate was higher than that of the synthetic medium [21].
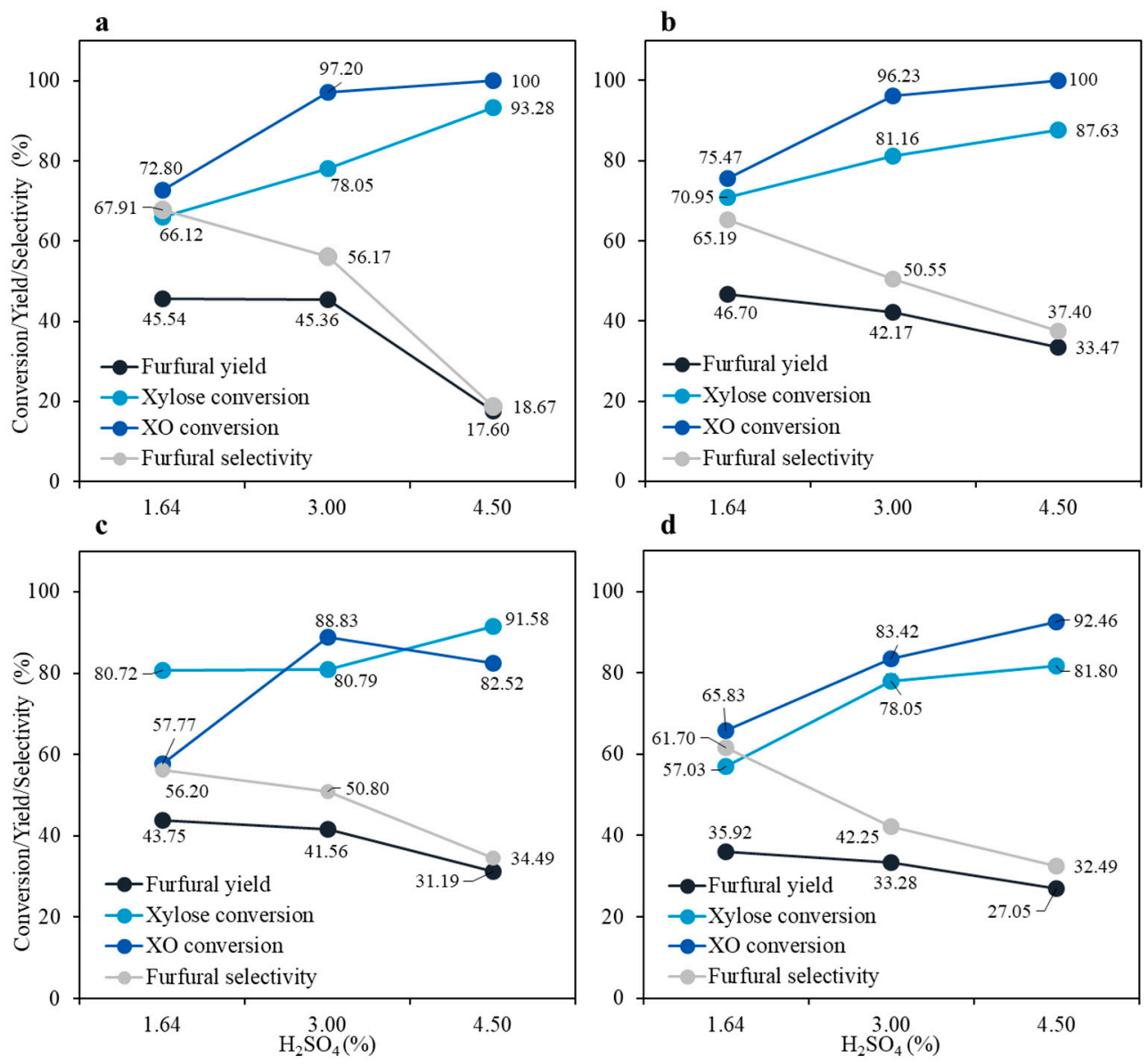

Figure 2. Xylose conversion, xylo-oligomer $(\mathrm{XO})$ conversion, furfural yield, and furfural selectivity depending on CSF and $\mathrm{H}_{2} \mathrm{SO}_{4}$ concentration (a) CSF 1.89, (b) CSF 1.92, (c) CSF 2.08, (d) CSF: 2.29. 


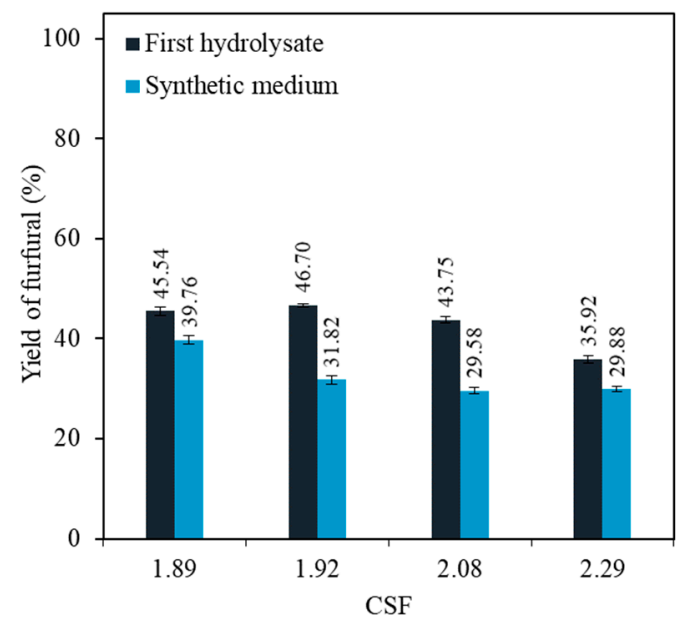

Figure 3. Furfural production from xylose in the first hydrolysate and synthetic medium, depending on CSF.

Table 3 shows the amount of humin produced at different $\mathrm{H}_{2} \mathrm{SO}_{4}$ concentrations. In general, furfural is unstable and polymerizes to form humins, owing to the condensation of furan and sugars. Therefore, the yield and selectivity of furfural from xylose and xylooligomer were reduced, owing to humin formation [29]. Here, humin production increased with increasing acid concentrations at each CSF. A high concentration of $\mathrm{H}_{2} \mathrm{SO}_{4}$ promoted humin formation and xylose dehydration, thereby reducing the furfural yield [30]. The yield of furfural was $46.71 \%$ with $1.64 \% \mathrm{H}_{2} \mathrm{SO}_{4}$ at CSF 1.92 . Under the same conditions, the rates of xylose and xylo-oligomer conversion to furfural were $70.95 \%$ and $75.47 \%$, respectively. The rate of xylose conversion was $>81 \%$ in $4.50 \% \mathrm{H}_{2} \mathrm{SO}_{4}$, whereas the furfural yield and selectivity were relatively low at $17.60-33.47 \%$ and $19.08-37.44 \%$, respectively, compared with those under other conditions.

Table 3. Humin production during dehydration of xylose into furfural at various $\mathrm{H}_{2} \mathrm{SO}_{4}$ concentrations (Unit: g).

\begin{tabular}{ccccc}
\hline \multirow{2}{*}{$\mathbf{H}_{\mathbf{2}} \mathbf{S O}_{\mathbf{4}}(\mathbf{\%})$} & \multicolumn{4}{c}{ Combined Severity Factors (CSF) } \\
\cline { 2 - 5 } & $\mathbf{1 . 8 9}$ & $\mathbf{1 . 9 2}$ & $\mathbf{2 . 0 8}$ & $\mathbf{2 . 2 9}$ \\
\hline 1.64 & $0.37(0.05)$ & $0.50(0.05)$ & $0.68(0.10)$ & $0.57(0.08)$ \\
3.00 & $0.49(0.09)$ & $0.79(0.06)$ & $0.70(0.07)$ & $0.90(0.09)$ \\
4.50 & $0.97(0.07)$ & $1.10(0.05)$ & $1.31(0.07)$ & $1.09(0.07)$ \\
\hline
\end{tabular}

The numbers in parentheses indicate the standard deviation.

Figure 4 shows the chemical composition of the second hydrolysate obtained by xylose dehydration of the first hydrolysate. The yield of furfural was $46.70 \%$ with $1.64 \% \mathrm{H}_{2} \mathrm{SO}_{4}$ at CSF 1.92 (Figure 2), whereas the production was high at $7.10 \mathrm{~g} / \mathrm{L}$ with $1.64 \% \mathrm{H}_{2} \mathrm{SO}_{4}$ at CSF 1.89. Furfural production decreased with increasing CSF. Under most reaction conditions, some xylose and xylo-oligomers were not converted to furfural and remained in the second hydrolysate after xylose dehydration, indicating that these reaction conditions were not appropriate for converting xylose to furfural.

At high $\mathrm{H}_{2} \mathrm{SO}_{4}$ concentrations, formaldehyde, acetaldehyde, and formic acid are byproducts of furfural decomposition; thus, formic acid concentrations increased slightly compared with those in the first hydrolysate $[21,26]$. Glucose undergoes multiple acidcatalyzed reactions and generates HMF as an intermediate, which can be hydrated to produce levulinic acid. Therefore, concentrations of glucose and HMF decreased compared with those in the first hydrolysate, and that of levulinic acid increased with increasing $\mathrm{H}_{2} \mathrm{SO}_{4}$ concentrations [31]. However, some acetic acid remained in the second hydrolysate at low $\mathrm{pH}$; these factors likely affected the yield of maleic acid. 

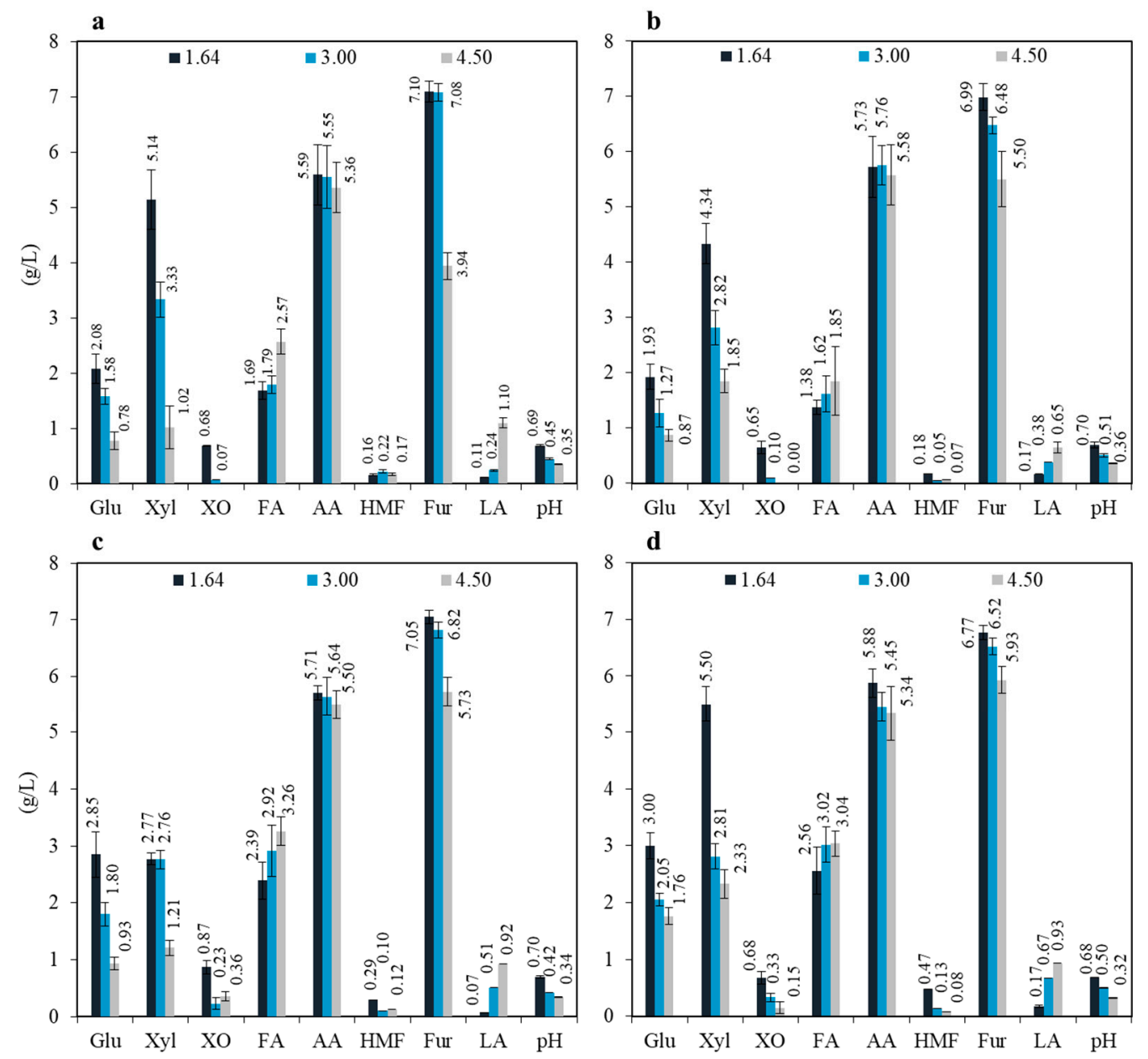

Figure 4. Sugars, xylo-oligomer, and degradation products in second hydrolysates, depending on $\mathrm{H}_{2} \mathrm{SO}_{4}$ concentrations (Glu: Glucose, Xyl: Xylose, XO: Xylo-oligomer, FA: Formic acid, AA: Acetic acid, HMF: 5-Hydroxymethylfurfural, Fur: Furfural, LA: levulinic acid, (a) CSF 1.89, (b) CSF 1.92, (c) CSF 2.08, (d) CSF: 2.29).

\subsection{Maleic Acid Production from the Second Hydrolysate}

Figure 5 shows maleic acid produced from the second hydrolysate using formic acid and $\mathrm{H}_{2} \mathrm{O}_{2}$. The process of maleic acid production from lignocellulosic biomass involves the hydrolysis of hexosans/pentosans to hexoses/pentoses, dehydration of hexose/pentose to $\mathrm{HMF}$ /furfural, and oxidation of HMF/furfural to maleic acid [11]. The catalytic conversion of pentoses to furfural consumes less energy and results in a higher conversion yield than that of hexoses to HMF. Therefore, furfural has been considered a cost-effective starting material for maleic acid production [32]. Here, the yield of maleic acid converted from furfural was calculated. Furfural was completely converted to maleic acid and other degradation products under all reaction conditions, but the maleic acid yield depended on the second hydrolysate. The high maleic acid yield was $92.90 \%$ at CSF 2.29 with $1.64 \%$ $\mathrm{H}_{2} \mathrm{SO}_{4}$. However, the optimal conditions for maximal maleic acid yield (91.44\%) were CSF 1.89 with $1.64 \% \mathrm{H}_{2} \mathrm{SO}_{4}$. Li et al. produced $95 \%$ maleic acid through a synthetic medium using $\mathrm{H}_{2} \mathrm{O}_{2}$ and formic acid [22]. The yield of maleic acid production obtained from the hydrolysate of the yellow poplar was slightly lower than that, but the results of this study confirmed that maleic acid can be produced from the hydrolysate of biomass. The oxidation reaction using $\mathrm{H}_{2} \mathrm{O}_{2}$ and an acid catalyst has low selectivity; thus, various degradation products, such as succinic acid, fumaric acid, and $2-(5 \mathrm{H})$-furanone, are produced in the maleic acid production process. Fumaric acid and 2-(5H)-furanone were intermediates of maleic acid production, at ratios $<2 \%$. 
The maleic acid yield was not proportional to the furfural content in the second hydrolysate. Furfural concentration reached $7.05 \mathrm{~g} / \mathrm{L}$ with $1.64 \% \mathrm{H}_{2} \mathrm{SO}_{4}$ at CSF 2.08, whereas maleic acid yield was $78.47 \%$. This implies that maleic acid production was affected by various degradation products as well as furfural in the second hydrolysate.
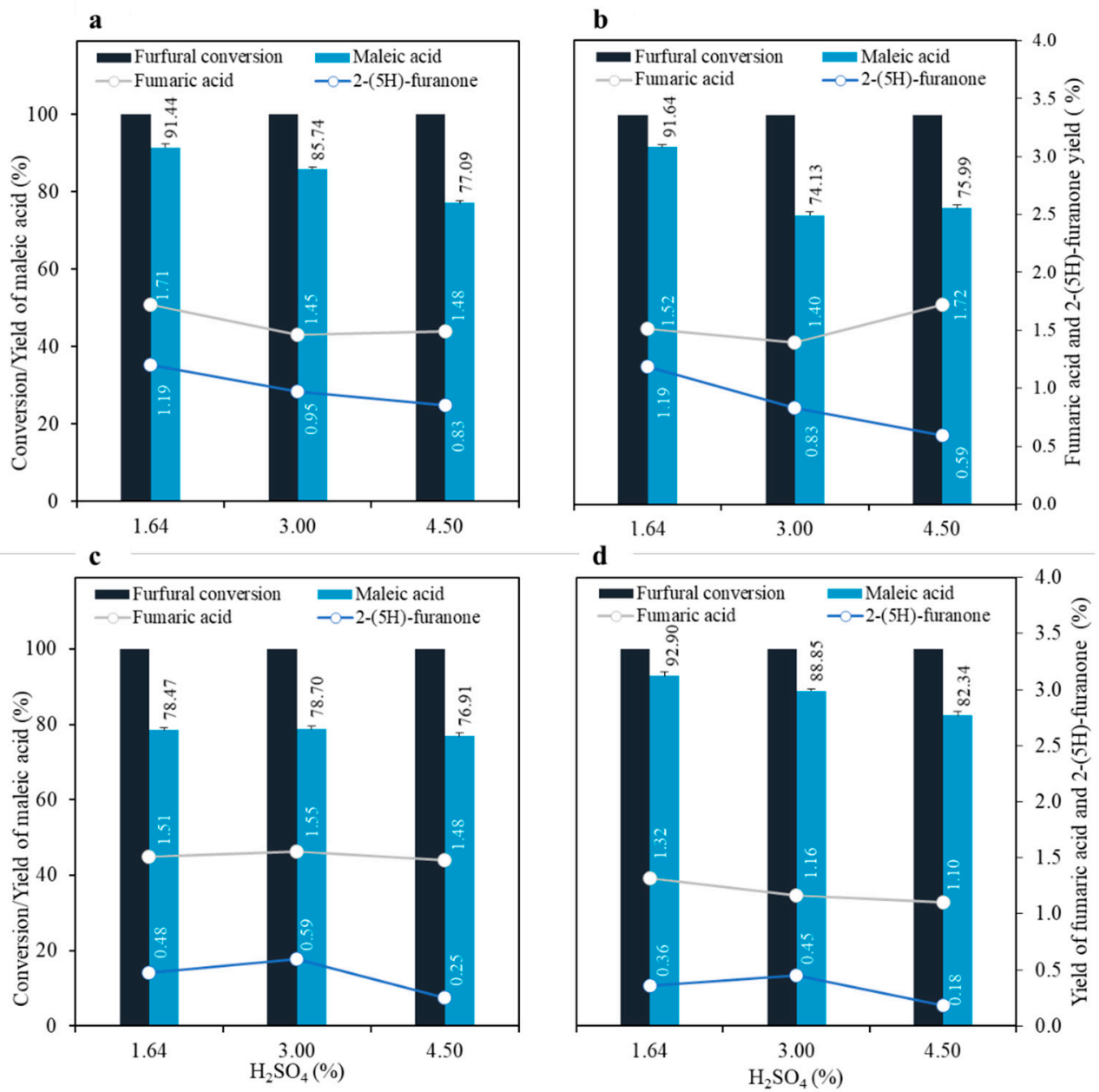

Figure 5. Maleic acid produced from furfural in the second hydrolysate using formic acid (4 mL) and $\mathrm{H}_{2} \mathrm{O}_{2}(1 \mathrm{~mL})$, depending on combined severity factors (CSFs) and $\mathrm{H}_{2} \mathrm{SO}_{4}$ concentration (a) CSF 1.89, (b) CSF 1.92, (c) CSF 2.08, (d) CSF: 2.29.

\subsection{Effects of Catalyst and Degradation Products on Maleic Acid Production from the Second Hydrolysate}

The yield of maleic acid produced at CSF 1.89 with $1.64 \% \mathrm{H}_{2} \mathrm{SO}_{4}$, depending on the ratios of formic acid to $\mathrm{H}_{2} \mathrm{O}_{2}$, was investigated (Figure 6). A synthetic medium was prepared with the same concentration of furfural as that in the second hydrolysate to determine the effects of degradation products in the second hydrolysate on maleic acid production. At a 4:1 ratio of formic acid $(4 \mathrm{~mL})$ and $\mathrm{H}_{2} \mathrm{O}_{2}(1 \mathrm{~mL})$, the maleic acid yield from the second hydrolysate was $91.44 \%$, whereas that from the synthetic medium with the same furfural concentration was $78.72 \%$. The second hydrolysate contained various degradation products, such as organic acids and furans. Therefore, other degradation products in the second hydrolysate positively affected maleic acid production. The highest yield of maleic acid in the synthetic medium was $87.32 \%$ at a $1: 1$ ratio of formic acid $(2.5 \mathrm{~mL})$ and $\mathrm{H}_{2} \mathrm{O}_{2}$ $(2.5 \mathrm{~mL})$. The yield was lower than that of the second hydrolysate. 


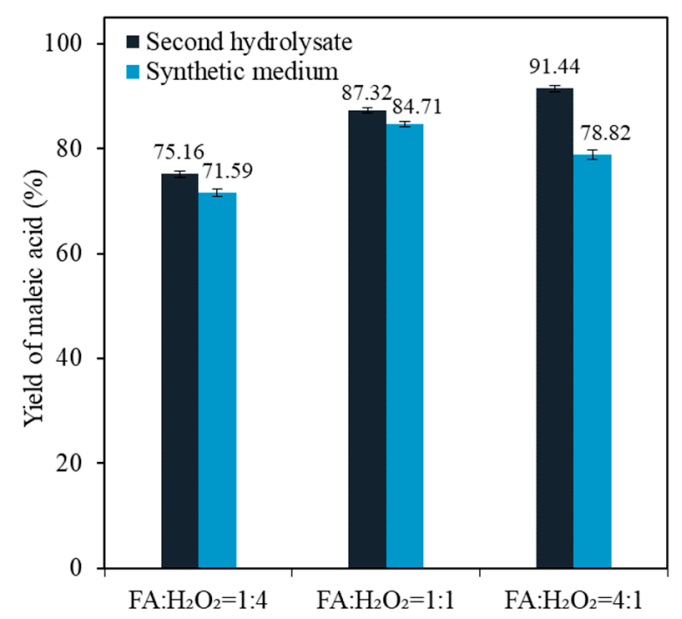

Figure 6. Maleic acid production from furfural in the second hydrolysate and synthetic medium, depending on the ratio of formic acid (FA) to $\mathrm{H}_{2} \mathrm{O}_{2}$.

Maleic acid production is affected by various factors such as the $\mathrm{H}_{2} \mathrm{O}_{2}$ concentration, catalyst type, and reaction temperature [33]. Li et al. reported that formic and acetic acids promote maleic acid production [22]. The effects of acetic and formic acids in the second hydrolysate on maleic acid production were investigated. A synthetic medium was prepared with similar furfural and organic acid contents to the second hydrolysate; then, the yield of maleic acid produced under formic acid: $\mathrm{H}_{2} \mathrm{O}_{2}(4: 1)$ was evaluated. Maleic acid yield slightly increased when acetic and formic acids were added to the synthetic medium, compared with that when only furfural was added (Table 4). Acetic and formic acids supposedly act as influencing factors to promote maleic acid production. However, the yield was lower than that in the second hydrolysate (91.44\%). This implies that other degradation products are involved in maleic acid production in addition to acetic and maleic acids.

Table 4. Maleic acid production from the synthetic medium using formic acid (4 mL) and $\mathrm{H}_{2} \mathrm{O}_{2}$ (1 mL).

\begin{tabular}{cc}
\hline Condition & Maleic Acid Yield (\%) \\
\hline Furfural & $78.82(0.99)^{\mathrm{a}}$ \\
Furfural + acetic acid & $79.11(0.08)^{\mathrm{b}}$ \\
Furfural + formic acid & $79.66(0.25)^{\mathrm{b}}$ \\
Furfural + acetic acid + formic acid & $79.94(0.78)^{\mathrm{c}}$ \\
\hline
\end{tabular}

Furfural, acetic acid, and formic acid concentration are similar to those in second hydrolysate. The same letters on the column are not significantly different from each other at $p<0.05$. The numbers in parentheses indicate the standard deviation.

Figure 7 shows the mass balance for maleic acid production from the hydrolysate of yellow poplar. The hydrolysate was obtained at CSF 1.89 , and furfural was produced in $1.64 \% \mathrm{H}_{2} \mathrm{SO}_{4}$. In total, $9.54 \mathrm{~g}$ of xylose was produced from $100 \mathrm{~g}$ of yellow poplar. After that, $1.08 \mathrm{~g}$ of furfural and $0.08 \mathrm{~g}$ of humin were produced from xylose, and $0.63 \mathrm{~g}$ of maleic acid was produced. These findings confirm that maleic acid can be produced from a hydrolysate derived from lignocellulosic biomass. 


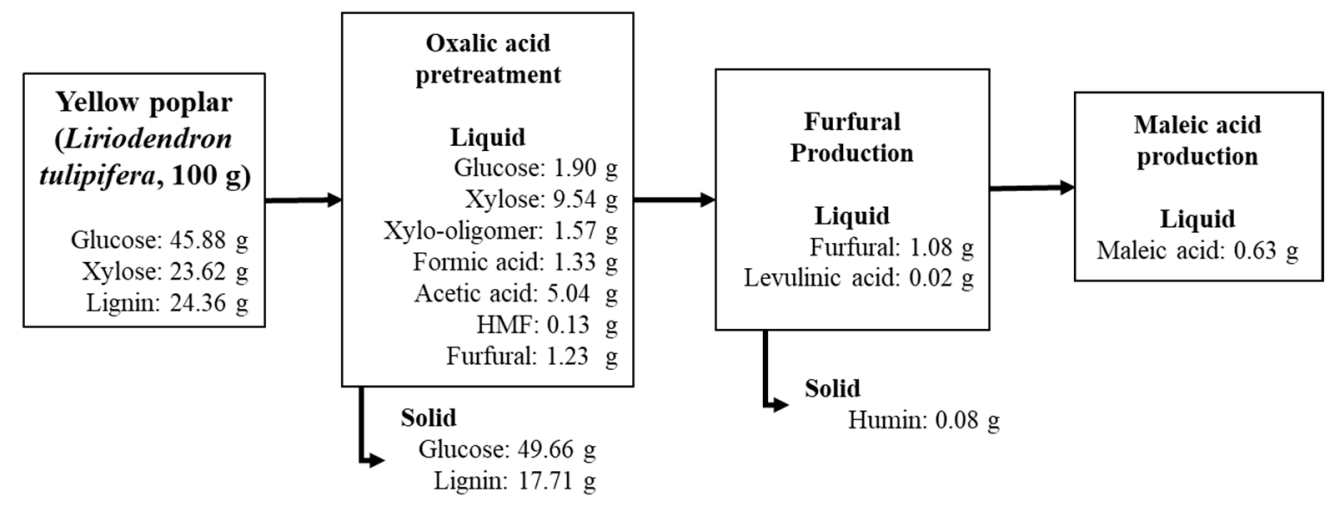

Figure 7. Mass balance for maleic acid production from lignocellulosic biomass.

\section{Conclusions}

Maleic acid was produced from xylose contained in a hydrolysate generated by the oxalic acid pretreatment of yellow poplar. Maleic acid was obtained by xylose dehydration, furfural oxidation, and $2(5 \mathrm{H})$-furanone oxidation in the hydrolysate. In the furfural production, the xylose conversion rate increased with increasing $\mathrm{H}_{2} \mathrm{SO}_{4}$ concentrations, but furfural selectivity decreased. This implies that xylose was not completely converted to furfural and various intermediates, and that interfering byproducts were generated. Maleic acid was produced using hydrolysates obtained from furfural production. The yield was improved by degradation products, such as formic and acetic acids. Overall, hydrolysates derived from yellow poplar contained an abundance of xylose, which is a suitable raw material for the production of furfural and maleic acid. The result of this study will contribute to the development of eco-friendly and efficient alternatives to fossil fuel-based processes.

Author Contributions: S.-Y.J.: Methodology, Data curation, Investigation, Formal analysis, Writingoriginal draft. J.-W.L.: Conceptualization, Data curation, Funding acquisition, Writing-review and editing. All authors have read and agreed to the published version of the manuscript.

Funding: This study was carried out with the support of the R\&D Program for Forest Science Technology (Project No. 2020228C10-2022-AC01) provided by the Korea Forest Service (Korea Forestry Pro-motion Institute).

Conflicts of Interest: The authors declare no conflict of interest.

\section{References}

1. Jönsson, L.J.; Martín, C. Pretreatment of lignocellulose: Formation of inhibitory by-products and strategies for minimizing their effects. Bioresour. Technol. 2016, 199, 103-112. [CrossRef] [PubMed]

2. Amin, F.R.; Khalid, H.; Zhang, H.; u Rahman, S.; Zhang, R.; Liu, G.; Chen, C. Pretreatment methods of lignocellulosic biomass for anaerobic digestion. AMB Express 2017, 7, 72. [CrossRef]

3. Bensah, E.C.; Mensah, M. Chemical pretreatment methods for the production of cellulosic ethanol: Technologies and innovations. Int. J. Chem. Eng. 2013, 2013. [CrossRef]

4. Fei, X.; Jia, W.; Wang, J.; Chen, T.; Ling, Y. Study on enzymatic hydrolysis efficiency and physicochemical properties of cellulose and lignocellulose after pretreatment with electron beam irradiation. Int. J. Biol. Macromol. 2020, 145, 733-739. [CrossRef]

5. Basak, B.; Jeon, B.-H.; Kim, T.H.; Lee, J.-C.; Chatterjee, P.K.; Lim, H. Dark fermentative hydrogen production from pretreated lignocellulosic biomass: Effects of inhibitory byproducts and recent trends in mitigation strategies. Renew. Sustain. Energy Rev. 2020, 133, 110338. [CrossRef]

6. Jia, Q.; Teng, X.; Yu, S.; Si, Z.; Li, G.; Zhou, M.; Cai, D.; Qin, P.; Chen, B. Production of furfural from xylose and hemicelluloses using tin-loaded sulfonated diatomite as solid acid catalyst in biphasic system. Bioresour. Technol. Rep. 2019, 6, 145-151. [CrossRef]

7. Luo, Y.; Li, Z.; Li, X.; Liu, X.; Fan, J.; Clark, J.H.; Hu, C. The production of furfural directly from hemicellulose in lignocellulosic biomass: A review. Catal. Today 2019, 319, 14-24. [CrossRef]

8. Thiyagarajan, S.; Franciolus, D.; Bisselink, R.J.; Ewing, T.A.; Boeriu, C.G.; Van Haveren, J. Selective production of maleic acid from furfural via a cascade approach combining photochemistry and electro-or biochemistry. ACS Sustain. Chem. Eng. 2020, 8, 10626-10632. [CrossRef] 
9. López, F.; García, M.; Feria, M.; García, J.; De Diego, C.; Zamudio, M.A.; Díaz, M. Optimization of furfural production by acid hydrolysis of Eucalyptus globulus in two stages. Chem. Eng. J. 2014, 240, 195-201. [CrossRef]

10. Mazar, A.; Jemaa, N.; Al Dajani, W.W.; Marinova, M.; Perrier, M. Furfural production from a pre-hydrolysate generated using aspen and maple chips. Biomass Bioenergy 2017, 104, 8-16. [CrossRef]

11. Hu, L.; Lin, L.; Wu, Z.; Zhou, S.; Liu, S. Recent advances in catalytic transformation of biomass-derived 5-hydroxymethylfurfural into the innovative fuels and chemicals. Renew. Sustain. Energy Rev. 2017, 74, 230-257. [CrossRef]

12. Ni, Y.; Bi, Z.; Su, H.; Yan, L. Deep eutectic solvent (DES) as both solvent and catalyst for oxidation of furfural to maleic acid and fumaric acid. Green Chem. 2019, 21, 1075-1079. [CrossRef]

13. Kubota, S.R.; Choi, K.-S. Electrochemical Valorization of Furfural to Maleic Acid. ACS Sustain. Chem. Eng. 2018, 6, 9596-9600. [CrossRef]

14. Teong, S.P.; Li, X.; Zhang, Y. Hydrogen peroxide as an oxidant in biomass-to-chemical processes of industrial interest. Green Chem. 2019, 21, 5753-5780. [CrossRef]

15. Araji, N.; Madjinza, D.D.; Chatel, G.; Moores, A.; Jérôme, F.; Vigier, K.D.O. Synthesis of maleic and fumaric acids from furfural in the presence of betaine hydrochloride and hydrogen peroxide. Green Chem. 2017, 19, 98-101. [CrossRef]

16. Deng, W.; Wang, Y.; Yan, N. Production of organic acids from biomass resources. Curr. Opin. Green Sustain. Chem. 2016, 2, 54-58. [CrossRef]

17. Liu, L.; Chang, H.-M.; Jameel, H.; Park, S. Furfural production from biomass pretreatment hydrolysate using vapor-releasing reactor system. Bioresour. Technol. 2018, 252, 165-171. [CrossRef] [PubMed]

18. Qing, Q.; Guo, Q.; Zhou, L.; Wan, Y.; Xu, Y.; Ji, H.; Gao, X.; Zhang, Y. Catalytic conversion of corncob and corncob pretreatment hydrolysate to furfural in a biphasic system with addition of sodium chloride. Bioresour. Technol. 2017, 226, 247-254. [CrossRef]

19. Wang, X.; Li, H.; Lin, Q.; Li, R.; Li, W.; Peng, F.; Ren, J. Efficient catalytic conversion of dilute-oxalic acid pretreated bagasse hydrolysate to furfural using recyclable ironic phosphates catalysts. Bioresour. Technol. 2019, 290, 121764. [CrossRef]

20. Jeong, S.-Y.; Lee, J.-W. Analysis of Factors Affecting Ethanol Fermentation of Hydrolysate Derived from the Oxalic Acid Pretreatment of Yellow Poplar (Liriodendron tulipifera). New Renew. Energy 2019, 15, 75-85. [CrossRef]

21. Li, W.-C.; Zhang, S.-J.; Xu, T.; Sun, M.-Q.; Zhu, J.-Q.; Zhong, C.; Li, B.-Z.; Yuan, Y.-J. Fractionation of corn stover by two-step pretreatment for production of ethanol, furfural, and lignin. Energy 2020, 195, 117076. [CrossRef]

22. Li, X.; Ho, B.; Lim, D.S.; Zhang, Y. Highly efficient formic acid-mediated oxidation of renewable furfural to maleic acid with $\mathrm{H}_{2} \mathrm{O}_{2}$. Green Chem. 2017, 19, 914-918. [CrossRef]

23. Alonso-Fagúndez, N.; Agirrezabal-Telleria, I.; Arias, P.; Fierro, J.; Mariscal, R.; Granados, M.L. Aqueous-phase catalytic oxidation of furfural with $\mathrm{H}_{2} \mathrm{O}_{2}$ : High yield of maleic acid by using titanium silicalite-1. RSC Adv. 2014, 4, 54960-54972. [CrossRef]

24. Sluiter, A.; Hames, B.; Ruiz, R.; Scarlata, C.; Sluiter, J.; Templeton, D. Determination of sugars, byproducts, and degradation products in liquid fraction process samples-Laboratory Analytical Procedure (LAP), NREL/TP-510-42623. 2006. Available online: https:/ / www.nrel.gov/docs/gen/fy08/42623.pdf (accessed on 8 February 2021).

25. Lee, C.B.T.L.; Wu, T.Y. A review on solvent systems for furfural production from lignocellulosic biomass. Renew. Sustain. Energy Rev. 2020, 110172. [CrossRef]

26. Choi, J.-H.; Jang, S.-K.; Kim, J.-H.; Park, S.-Y.; Kim, J.-C.; Jeong, H.; Kim, H.-Y.; Choi, I.-G. Simultaneous production of glucose, furfural, and ethanol organosolv lignin for total utilization of high recalcitrant biomass by organosolv pretreatment. Renew. Energy 2019, 130, 952-960. [CrossRef]

27. Kim, E.S.; Liu, S.; Abu-Omar, M.M.; Mosier, N.S. Selective conversion of biomass hemicellulose to furfural using maleic acid with microwave heating. Energy Fuels 2012, 26, 1298-1304. [CrossRef]

28. Raman, J.K.; Gnansounou, E. Furfural production from empty fruit bunch-A biorefinery approach. Ind. Crops Prod. 2015, 69, 371-377. [CrossRef]

29. Yu, Q.; Bai, R.; Wang, F.; Zhang, Q.; Sun, Y.; Zhang, Y.; Qin, L.; Wang, Z.; Yuan, Z. A sustainable system for maleic acid synthesis from biomass-derived sugar. J. Chem. Technol. Biotechnol. 2020, 95, 751-757. [CrossRef]

30. Woiciechowski, A.L.; Neto, C.J.D.; de Souza Vandenberghe, L.P.; de Carvalho Neto, D.P.; Sydney, A.C.N.; Letti, L.A.J.; Karp, S.G.; Torres, L.A.Z.; Soccol, C.R. Lignocellulosic biomass: Acid and alkaline pretreatments and their effects on biomass recalcitranceConventional processing and recent advances. Bioresour. Technol. 2020, 304, 122848. [CrossRef]

31. Chen, H.; Qin, L.; Yu, B. Furfural production from steam explosion liquor of rice straw by solid acid catalysts (HZSM-5). Biomass Bioenergy 2015, 73, 77-83. [CrossRef]

32. Esteban, J.; Yustos, P.; Ladero, M. Catalytic processes from biomass-derived hexoses and pentoses: A recent literature overview. Catalysts 2018, 8, 637. [CrossRef]

33. Mariscal, R.; Maireles-Torres, P.; Ojeda, M.; Sádaba, I.; Granados, M.L. Furfural: A renewable and versatile platform molecule for the synthesis of chemicals and fuels. Energy Environ. Sci. 2016, 9, 1144-1189. [CrossRef] 